\title{
Comprehension of workplace safety signs: A case study in Shiraz industrial park
}

\author{
Zamanian Z, $\mathrm{PhD}^{1}$, Afshin A, BSc ${ }^{2}$, Davoudiantalab $\mathrm{AH}, \mathrm{BSc}^{2}$, Hashemi $\mathrm{H}, \mathrm{PhD}^{3 *}$ \\ 1- Associate Prof., Dept of Occupational Health, School of Health, Shiraz University of Medical Sciences, Shiraz, Iran. \\ 2- BSc, Dept of Occupational Health, School of Health, Student Research Committee, Shiraz University of Medical \\ Sciences, Shiraz, Iran. 3- Lecturer, Dept of Environmental Health Engineering, School of Health, Shahrekord University \\ of Medical Sciences, Shahrekord, Iran.
}

\begin{abstract}
Received: May 2013, Accepted: March 2014

Background: Safety signs provide information as well as instructions concerning the hazard or dangers in the workplace. The correct comprehension of these signs is very important for doing the necessary feedback in the specific situation which are described.

Materials and Methods: In this descriptive study, the comprehension of 10 selected safety signs were investigated in 53 randomly selected employees of an industrial company in Shiraz. The comprehension test was carried out with the aid of a standard questionnaire obtained from ISO 9186-1:2007.

Results: In this study the mean comprehension scores of the tested signs were 65.95 percent with standard deviation if 28.7. The highest and lowest comprehension scores were for "use hearing protectors" and "biological hazard" respectively. The comprehension of 40 percent of the tested safety signs was lower than the minimum acceptable values of ISO 3864 and ANSI Z535.3 standards.

Conclusion: This study showed that there is a significant difference in comprehensions of tested safety signs. For full comprehension of safety signs it is necessary to train the employees or add supplementary texts to the symbols in some cases.
\end{abstract}

Key words: Safety, Signs, Workplace, Color, Culture

\section{Introduction}

Safety signs are one of the methods of informing and warning the staff regarding the type and severity of the workplace dangers and are used considering the risk of dangers where necessary (1-3). According to International Standard Organization (ISO) 17724: 2003, a safety sign is a sign which transfers a safety message. In fact, when the signs are accompanied by colors, geometrical figures and graphical signs, they transfer a specific safety message (4).

In general, safety signs may represent a danger, dangerous conditions, or consequences of being exposed to dangers $(5,6)$. Also, some signs include cautions and safety recommendations for the individuals who execute unsafe and dangerous behaviors; and, at the same time, show the way to prevent such behaviors (3). Based on some studies, various factors such as the level of education, working experience, working time (7-9), type of safety signs $(10,11)$, background color of safety signs and training (12-14) affect the individuals' comprehension of the safety signs. Yet, cultural differences are also effective in comprehension of safety signs (15).

For instance, Chan et al. conducted a study in U.S. and showed that the Chinese and

\footnotetext{
Corresponding author: Hassan Hashemi, Dept of Environmental Health Engineering, School of Health, Shahrekord University of Medical Sciences, Shahrekord, Iran.

Email: hashemi@hlth.mui.ac.ir
} 
Korean residents of U.S. comprehend the safety signs less than the Americans. Besides, comprehension of some signs was quite difficult for non-Americans (16).

Furthermore, safety signs can be beneficial if they are diverse and attractive. Also, people should be able to understand these signs because in cases they do not understand the messages, they will not be able to recognize the dangers and take the necessary precautions (17). According to National Safety Council, deficiency in the correct information transfer by the safety signs is the third common factor in investigation of the incidents (18). The studies conducted by Chan \& Chan showed that safety signs have to be evaluated regarding their correct comprehension by people before use (19). Thus, the staff's familiarity with these signs is of great importance in order to have a correct understanding of the signs and their responsibilities in case of being exposed to dangers.

Based on what was mentioned above and considering the fact that most safety signs in Iran are adopted from other countries, the present study aims to determine the comprehensibility of the workplace safety signs and present strategies for improving their comprehensibility.

\section{Materials and Methods}

The present cross-sectional study was conducted in one of the industrial companies of Shiraz, Iran in 2013. According to the sections 2, 3 and 6 of ISO 9186-1, at least 50 individuals from each country should take part in each safety signs comprehension test. Therefore, 53 non-colorblind staff of the above mentioned company were randomly selected for taking part in the safety signs comprehension test using the table of random numbers. The study data were gathered using the standard questionnaire of International Standard Organization (20) on quantification of safety signs comprehension. The validity of the questionnaire was confirmed by 3 safety and ergonomics professors. This questionnaire contained open-ended questions and consisted of 4 sections: 1 - how to complete the questionnaire, 2demographic characteristics including age, sex, level of education, health status and type of probable disability, 3- an example of how to complete the safety signs comprehension test and 4- the safety signs comprehension test.

After all, ten $8 \times 8$ colored, back labeled signs, including 4 prohibition signs, 2 mandatory signs, 2 warning signs and 2 signs related to safe conditions, were randomly selected and glued on ten A4 papers. The used safety signs and their meanings are presented in table 2.

The data were analyzed using the SPSS statistical software (v. 11.5) and the staff's responses to the safety signs comprehension test were compared with the acceptable ranges of American National Standards Institute (ANSI) Z535.3 (21)and ISO 3864 (22)standards. Since the wrong answers which reversely transfer the safety signs' meanings are highly important, these answers were separately investigated.

\section{Results}

In this study, $89.1 \%$ of the participants were male and the rest were female. In addition, $35.5 \%, 44.6 \%, 19.2 \%$ and $7 \%$ of the subjects were 20-30, 31-40, 41-50 and $\geq 51$ years old, respectively. Twenty three point eight percent of the study's participants had under high school diploma degrees, $52.1 \%$ had high school diplomas and $25.1 \%$ had academic degrees (table1). It should be noted that all the study subjects were healthy. 
Table 1: Some demographic characteristics in one industrial company $(n=53)$

\begin{tabular}{c|c|c|c|l|l}
\hline \multicolumn{2}{c|}{ Age } & \multicolumn{2}{c|}{ Job tenure } & \multicolumn{2}{l}{ level of education } \\
\hline $20-30$ & $35.5 \%$ & $<5$ & $43.5 \%$ & Under & $23.8 \%$ \\
$31-40$ & $44.6 \%$ & $5-10$ & $42.2 \%$ & Diploma & $52.1 \%$ \\
$41-50$ & $19.2 \%$ & $10-15$ & $7.5 \%$ & Diploma & $25.1 \%$ \\
$\geq 51$ & $0.7 \%$ & $15-20$ & $3.4 \%$ & academic & \\
\hline
\end{tabular}

The tested safety signs and their comprehension rate by the study subjects are presented in table 2 .

As the table depicts, the mean score of correct comprehension (correct responses) was $70.94+27.38$.

Table 2: The tested safety signs and their comprehension by the study subjects

\begin{tabular}{|c|c|c|c|c|c|c|c|c|c|c|c|}
\hline \multirow{3}{*}{ Sign } & \multirow{3}{*}{ Meaning } & \multicolumn{10}{|c|}{ Responses } \\
\hline & & \multicolumn{2}{|c|}{ Correct } & \multicolumn{2}{|c|}{ Incorrect } & \multicolumn{2}{|c|}{ Reverse } & \multicolumn{2}{|c|}{ I don't know } & \multicolumn{2}{|c|}{ No response } \\
\hline & & Number & $\%$ & Number & $\%$ & Number & $\%$ & Number & $\%$ & Number & $\%$ \\
\hline & First aid & 49 & 92.45 & 4 & 7.54 & 0 & 0 & 0 & 0 & 0 & 0 \\
\hline & $\begin{array}{l}\text { Use ear } \\
\text { protection }\end{array}$ & 53 & 100 & 0 & 0 & 0 & 0 & 0 & 0 & 0 & 0 \\
\hline & $\begin{array}{l}\text { Arrange } \\
\text { correctly }\end{array}$ & 24 & 45.28 & 25 & 47.16 & 1 & 1.88 & 2 & 3.77 & 1 & 1.88 \\
\hline & $\begin{array}{c}\text { Toxic } \\
\text { material }\end{array}$ & 49 & 92.45 & 3 & 5.66 & 0 & 0 & 1 & 1.88 & 0 & 0 \\
\hline & $\begin{array}{l}\text { Biological } \\
\text { danger }\end{array}$ & 16 & 30.18 & 16 & 30.18 & 0 & 0 & 18 & 33.96 & 3 & 5.66 \\
\hline & $\begin{array}{c}\text { No } \\
\text { smoking }\end{array}$ & 52 & 98.11 & 1 & 1.88 & 0 & 0 & 0 & 0 & 0 & 0 \\
\hline & $\begin{array}{l}\text { Do not } \\
\text { operate the } \\
\text { device }\end{array}$ & 19 & 35.84 & 29 & 54.71 & 0 & 0 & 2 & 3.77 & 3 & 5.66 \\
\hline & $\begin{array}{c}\text { Not } \\
\text { drinking } \\
\text { water }\end{array}$ & 41 & 77.35 & 8 & 15.09 & 0 & 0 & 3 & 5.66 & 1 & 1.88 \\
\hline & $\begin{array}{l}\text { Don't } \\
\text { repair }\end{array}$ & 27 & 50.94 & 20 & 37.73 & 0 & 0 & 5 & 9.43 & 1 & 1.88 \\
\hline & $\begin{array}{c}\text { Emergency } \\
\text { exit }\end{array}$ & 46 & 86.79 & 2 & 3.77 & 2 & 3.77 & 1 & 1.88 & 2 & 3.77 \\
\hline & Mean & 37.6 & 70.94 & 10.8 & 20.37 & 0.3 & 0.56 & 3.2 & 6.03 & 1.1 & 2.07 \\
\hline Total & $\begin{array}{l}\text { Standard } \\
\text { deviation }\end{array}$ & 14.51 & 27.38 & 10.79 & 20.37 & 0.67 & 1.27 & 5.43 & 10.24 & 1.19 & 2.25 \\
\hline
\end{tabular}


Comparison of the subjects' comprehension of the safety signs is shown in Figure 1. As it can be seen, the highest and lowest rates of correct comprehension were related to "Use ear protection" (100\%) and "Biological danger" $(30.2 \%)$ signs, respectively.
In addition, most of the incorrect responses were related to "Do not operate the device" (54.7\%) and "Arrange correctly" (42.2\%) signs. Besides, 2 subjects had provided reverse responses for the "Emergency exit" sign.

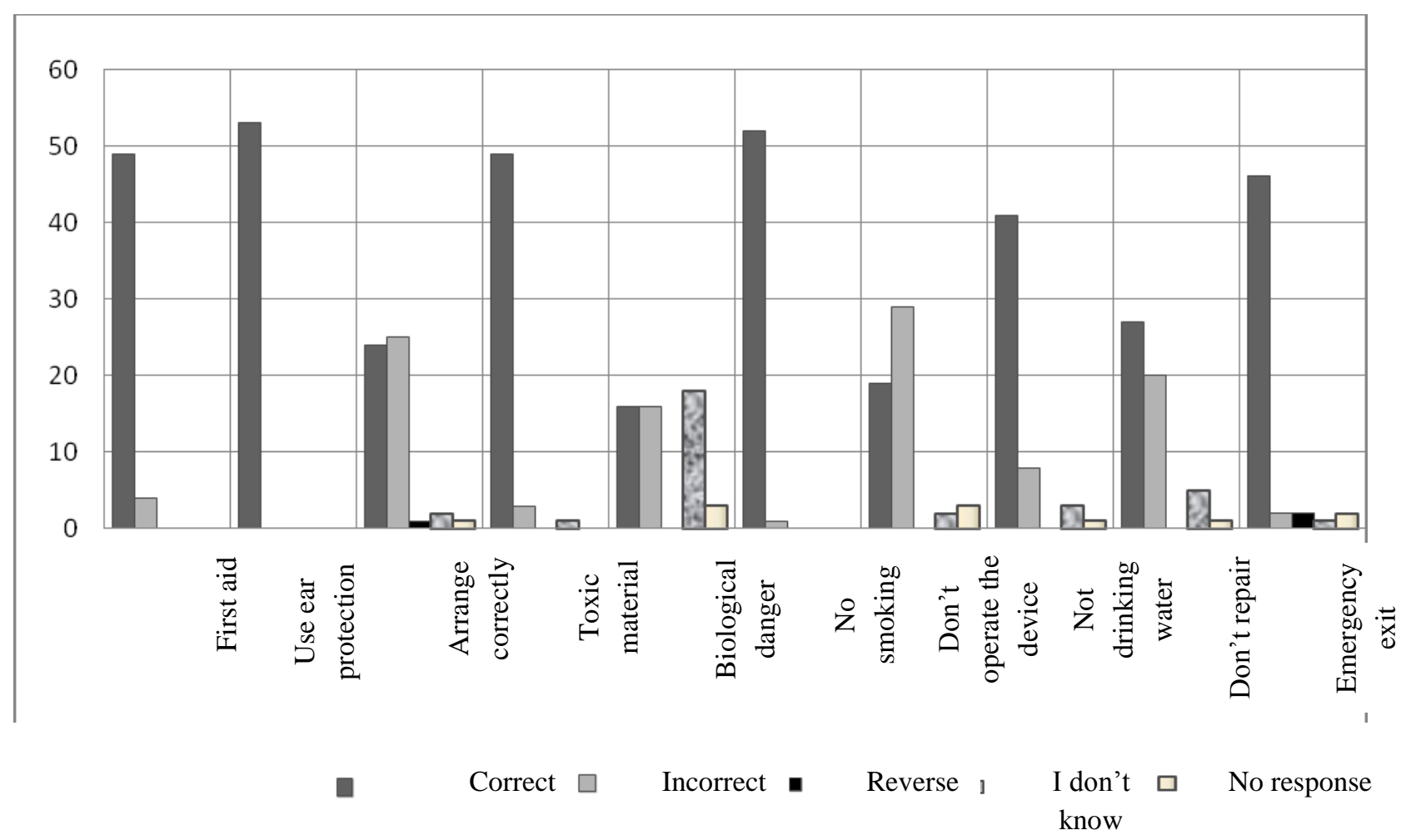

Figure 1: The subjects' comprehension of the studied safety signs

\section{Discussion}

In the present study, correct responses were considered as the criteria for correct comprehension of the safety signs. The relatively high standard deviation of the correct responses $(27.38 \%)$ shows that the comprehension of these safety signs was significantly different from each other and each sign has had its own specific comprehension pattern. According to the results, the mean of correct responses to the studied safety signs was $70.94 \%$ which is in agreement with the study performed by $\mathrm{Ng}$ et al (3) on the Chinese students in Hong Kong. In that study, $67.54 \%$ of the participants answered the study safety signs correctly. Based on the standard number ISO 3864 (22) of the International Standard Organization and standard number ANSI Z535.3 of ANSI (21), the mean of correct responses to safety signs must be at least $67 \%$ and $85 \%$ of the study subjects, respectively. 
The results show no significant relation between some demographic characteristics such as age, job and level of education with the mean of the correct responses to safety signs $\left(\mathrm{P}_{\text {val }}>0.05\right)$. These results could be existed due to the small size of the sample.

According to Table 2, the mean of correct responses to 5 signs investigated in this study; i.e., "First aid", "Use ear protection", "Toxic material", "No smoking" and "Emergency exit", was above 85\%. Therefore, they had the minimum rate of American National Standards Institute (21). Considering the International Standard Organization's standards, in addition to the 5 above mentioned signs, the mean of correct comprehension of "Not drinking water" sign was also above $67 \%$. Thus, the mean of correct responses was below the acceptable ranges in ISO 3864 and ANSI Z535.3 (21) standards in $40 \%$ of the signs, including "Arrange correctly", "Biological danger", "Do not operate the device" and "Don't repair". In the study by $\mathrm{Ng}$ et al., (3) the mean of correct comprehension of $60 \%$ of the studied safety signs was below the acceptable ranges of ISO 3864 (22) and ANSI Z535.3 (21) standards. Also, in the study of Papastavrou and Lehto (14) only $5.88 \%$ and $35.29 \%$ of the study signs satisfied the acceptable ranges of ANSI (21) and ISO (20-22). On the other hand, Manop conducted a study and showed that $79 \%$ of the studied safety signs in Thailand chemical industries achieved the acceptable criterion of $85 \%$ (10). Yet, one other study which was performed in the Intensive Care Units (ICUs) of China showed that among the tested signs, 3 and 4 satisfied the acceptable ranges of ANSI and ISO, respectively (19).

Based on what was mentioned above, it seems that the differences, in the correct comprehension rates of safety signs in various studies are related to the cultural differences, the features of the study population, previous training and the commonness of the sign in the study industry.

In the present study, although the staff knew the overall concepts of the safety signs, the results showed that the percentage of incorrect answers to the signs which were less used in that industry was significantly high. For instance, $57.4 \%$ of the study subjects had incorrectly answered to "Do not operate the device" sign. In other words, this sign was not able to completely introduce itself and had low self-explanation. This was also the case for "Biological danger" sign which received the lowest rate of correct responses $(30.18 \%)$ because it was quite uncommon in the study industry. In contrast to the other signs, the form of this sign was also quite unfamiliar to the study subjects. On the other hand, $98.11 \%$ of the participants provided correct answers to "No smoking" sign because this sign is quite common in both the society and the workplace. Overall, the signs which were more commonly used in the industry had a higher comprehension level. This is in line with the results of other studies conducted on the issue $(14,19)$.

In the case that the concept of a safety sign is reversely transferred, its utilization in safety conditions is of utmost importance. According to ANSI Z535.3 (21) standard, the acceptable rate of reverse responses is $5 \%$ and a sign with above 5\% reverse responses is considered as a confusing one. As Table 2 depicts, in this study, 2 reverse responses $(3.8 \%)$ were related to "Emergency exit" sign and $1(1.88 \%)$ was related to "Arrange correctly" sign, which is within the acceptable range of ANSI standard. In other words, based on ISO 3864 (22) standard, the designed safety signs were appropriate and not confusing. In spite of the fact that the "Emergency exit" sign is one of the main 
safety signs and all the industrial workers are expected to be familiar with this sign, $11.4 \%$ of the responses to this sign were incorrect, reverse and no response and $1.9 \%$ were "I don't know". This might be due to the lack of the staff's training regarding the meaning of this sign. In such cases, the text is recommended to be written under the sign.

\section{Conclusions}

The findings of the current study showed differences in the rate of correct comprehension of different study safety signs. In this study, the rate of correct comprehension of $40 \%$ of the safety signs was below the minimum acceptable range of ISO 3864 and ANSI Z535.3 standards. The staff's familiarity with the signs, training them regarding the meanings of safety signs and sometimes writing texts under the signs can significantly affect their comprehension of the signs.

\section{Acknowledgements}

The present study was financially supported by Student Research Committee of the research vice-chancellor of Shiraz University of Medical Sciences, Shiraz, Iran (No; 905867).

\section{Conflict of interest: Non declared}

\section{References}

1. Cox S, Jones B, Rycraft H. Behavioral approaches to safety management within UK reactor plants. Saf Sci 2004; 42(9): 825-39.

2. Luria G, Rafaeli A. Testing safety commitment in organizations through interpretations of safety artifacts. J Safety Res 2008; 39(5):519-28.

3. Ng, AWY, Lo HWC, Chan AHS. Measuring the usability of safety signs: A use of System Usability Scale (SUS). Proceeding of the International Multi Conference of Engineer and Computer Scientists; 2011 March 16-18; Hong Kong. IMECS 2011; 2. P1-6.

4. ISO 17724:2003 graphical symbolsvocabulary. International Organization for Standardization, Geneva, Switzerland. Available from:

http://www.iso.org/iso/catalogue_detail.htm? csnumber $=33186$

5. Wogalter MS, Conzola VC, Smith-Jackson TL. Research-based guidelines for warning design and evaluation. Appl Ergon 2002; 33(3):219-30.

6. Jorgensen F, Wentzel-Larsen T. Optimal use of warning signs in traffic. Accid Anal Prev 1999; 31(6):729-38.

7. Piamonte DPT, Abeysekera JDA, Ohlsson K. Understanding small graphical symbols: a cross-cultural study. Int J Ind Ergon 2001; 27(6):399-404.

8. Edworthy J. The design and implementation of non-verbal auditory warnings. Appl Ergon 1994; 25(4):202-10.

9. Belz SM, Robinson GS, Casali JG. A new class of auditory warning signals for complex systems: auditory icons. Hum Factors 1999; 41(4):608-18.

10. Chunin M. Factors determining compliance with safety signs in industrial settings. $[\mathrm{PhD}$ Thesis]. Sydney: University of New South Wales; 2001.

11. Lehto M, Salvendy G. Warnings: a supplement not a substitute for other approaches to safety. Ergonomics 1995; 38(11):2155-63.

12. Chan $\mathrm{AH}, \mathrm{Ng} \mathrm{AW}$. Effects of sign characteristics and training methods on safety sign training effectiveness. Ergonomics 2010; 53(11):1325-46.

Yu RF, Chan AHS, Salvendy G. Chinese perceptions of implied hazard for signal words and surround shapes. Human Factors and Ergonomics in Manufacturing \& Service Industries 2004; 14(1):69-80.

13. Papastavrou JD, Lehto MR. Improving the effectiveness of warnings by increasing the appropriateness of their information content: some hypotheses about human compliance. Saf Sci 1996; 21(3):175-89. 
14. Gherardi S, Nicolini D. Learning the trade: A culture of safety in practice. Organization 2002; 9(2):191-223.

15. Chan AHS, Han SH, Ng AWY, Park W. Hong Kong Chinese and Korean comprehension of American security safety symbols. Int J Ind Ergon 2009; 39(5):835-50.

16. Arphorn S, Augsornpeug N, Srisorrachatr S, Pruktharathikul V. Comprehension of safety signs for construction workers: Comparison of existing and newly designed signs. J Hum Ergol 2003; 32(7):87-94.

17. NSC 2008. National Safety Council annual report. National Safety Council.

Available from: http://www.nsc.org/news

18. Chan KL. Chan AHS. Understanding industrial safety signs: implications for occupational safety management. Industrial Management \& Data Systems 2011; 111(9):1481-510.
19. ISO 9186-1:2007. Graphiclal symbols-test methods-part 1: Methods for testing comprehensibility. International Organization for Standardization, Geneva, Switzerland. Available from:

http://www.iso.org/iso/catalogue_detail.htm? csnumber $=41090$

20. America. American National Standards Institute. American national standard for Criteria for safety symbols. National Electrical Manufacturers Association. NewYork; 2011.

21. ISO 3864-2:2004. Graphical symbols-safety colours and safety signs-part 2: Design principles for product safety labels. International Organization for Standardization. Geneva, Switzerland. Available from: http://www.iso.org/iso/catalogue_detail.htm? csnumber $=31020$. 